(6) OPEN ACCESS

\title{
The mental health of deployed UK maritime forces
}

\author{
Dean Whybrow, ${ }^{1}$ Norman Jones, ${ }^{2}$ Charlotte Evans, ${ }^{3}$ Darren Minshall, ${ }^{3}$ Darren Smith, ${ }^{4}$ \\ Neil Greenberg ${ }^{2}$
}

${ }^{1}$ School of Healthcare Sciences, College of Biomedical and Life Sciences, Cardiff University, Cardiff, UK

${ }^{2}$ Academic Department of Military Mental Health, King's College, London, UK

${ }^{3}$ Department of Community Mental Health, Defence

Primary Health Care Service, Portsmouth, UK

${ }^{4}$ Department of Community Mental Health, Defence Primary Health Care Service, Faslane, UK

\section{Correspondence to} Dean Whybrow, School of Healthcare Sciences, College of Biomedical and Life Sciences, Cardiff University, 6th floor, Eastgate House, 35-43

Newport Rd, Cardiff CF24 $O A B, U K$;

whybrowd@cardiff.ac.uk

Received 19 March 2015 Revised 15 July 2015 Accepted 22 July 2015 Published Online First 11 August 2015

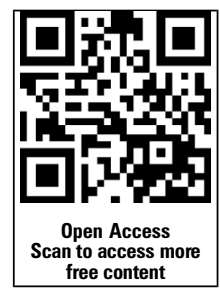

\section{SLinked}

- http://dx.doi.org/10.1136/ oemed-2015-103104

\section{CrossMark}

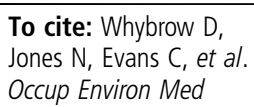

To cite: Whybrow $D$ Jones N, Evans C, et al. Occup Environ Med 2016;73:75-82.

\section{ABSTRACT}

Objectives To establish the level of psychological symptoms and the risk factors for possible decreased mental health among deployed UK maritime forces. Methods A survey was completed by deployed Royal Navy (RN) personnel which measured the prevalence of common mental disorder (CMD), post-traumatic stress disorder (PTSD) and potential alcohol misuse. Military and operational characteristics were also measured including exposure to potentially traumatic events, problems occurring at home during the deployment, unit cohesion, leadership and morale. Associations between variables of interest were identified using binary logistic regression to generate ORs and $95 \% \mathrm{Cls}$ adjusted for a range of potential confounding variables.

Results In total, $41.2 \%(n=572 / 1387)$ of respondents reported probable CMD, 7.8\% ( $n=109 / 1389)$ probable PTSD and $17.4 \%(n=242 / 1387)$ potentially harmful alcohol use. Lower morale, cohesion, leadership and problems at home were associated with CMD; lower morale, leadership, problems at home and exposure to potentially traumatic events were associated with probable PTSD; working in ships with a smaller crew size was associated with potentially harmful alcohol use. Conclusions CMD and PTSD were more frequently reported in the maritime environment than during recent land-based deployments. Rates of potentially harmful alcohol use have reduced but remain higher than the wider military. Experiencing problems at home and exposure to potentially traumatic events were associated with experiencing poorer mental health; higher morale, cohesion and better leadership with fewer psychological symptoms.

\section{INTRODUCTION}

Military personnel face a range of relatively unique occupational stressors, which may impact on their mental health. These include the requirement to deploy into challenging environments where the threat of injury or death can be substantial. There has been a considerable amount of research carried out among UK military personnel when they have returned to safe base locations suggesting that, for most personnel, deployment does not seem to be directly linked to poorer mental health. However, compared to personnel deployed in mainly logistic and support roles, higher rates of mental ill-health have been found among troops in combat roles and among deployed reservists when compared to nondeployed reserves. ${ }^{1}$ Studies examining the mental health of service personnel while carrying out their primary duties in the deployed environment are, however, much less common.

\section{What this paper adds}

- Previous research suggests a relatively high rate of mental disorder among UK maritime forces.

- No previous study has examined the prevalence of mental disorder during a maritime deployment specifically.

- In total $41.2 \%$ ( $n=572 / 1387)$ of respondents reported probable common mental disorder (CMD), 7.8\% ( $n=109 / 1389)$ probable post-traumatic stress disorder (PTSD) and $17.4 \%$ $(n=242 / 1387)$ potentially harmful alcohol use.

- Lower morale, cohesion, leadership and problems at home were associated with CMD; lower morale, leadership, problems at home and exposure to potentially traumatic events were associated with probable PTSD; working in smaller ships was associated with potentially harmful alcohol use.

- Further investigation is required to establish whether collaborative approaches during deployment between welfare support and medical services may have benefits for the mental health of deployed maritime personnel.

Common mental disorders (CMD) include conditions such as mood, anxiety and neurotic spectrum disorders. ${ }^{2}$ One previous study of the mental health status of UK Armed Forces (UK AF) personnel serving in the Falkland Islands reported a probable CMD rate of $32 \%$. $^{3}$ When this study was conducted (March 2001), no hostilities had taken place in the Falklands for many years and personnel were deployed in a largely peace support role. More recent studies of UK AF personnel engaged in land-based combat operations have been conducted. In Iraq in 2009, a deployment survey found that $21 \%$ of personnel reported symptoms of probable CMD and $3.4 \%$ had symptoms of probable PTSD. ${ }^{4}$ Two further studies using a similar methodology were conducted in Afghanistan in 2010 and 2011. In these studies, rates of probable CMD were $17 \%$ and $16 \%$ respectively and probable PTSD rates were $2.8 \%$ and $1.8 \% .^{5}$ Although the consumption of alcohol was allowed during the period of the Falkland Islands deployment study, rates of consumption were not measured. The use of alcohol was prohibited during the Iraq and Afghanistan deployments.

A postal survey of Royal Navy (RN) personnel was carried out in 1999 by the UK Institute of Naval Medicine; this was repeated with different 
participants in $2004 .^{6}$ The study achieved good response rates; $78 \%(n=1331)$ and $67 \%(n=1172)$, respectively. Of note, the study utilised the General Health Questionnaire-12 (GHQ-12) to measure strain with a cut-off of greater than four equalling caseness. The current paper also utilised the GHQ-12 with the same cut-off point, but consistent with previous studies defined caseness as indicative of probable CMD. ${ }^{45}$

In the above Bridger et al, ${ }^{6}$ paper, CMD rates were stable between the two survey points; these were 32\% in 1999 and $34 \%$ in 2004 . There was a significantly higher rate of CMD among females and those serving at sea, rather than being land based, at both times. The rates for personnel at sea were $37 \%$ and 38\% among males and 57\% and 52\% among females. Overall, the rate of CMD for all surveyed personnel deployed at sea was $41 \%(n=410 / 999)$. In a further study of RN personnel, the earlier study procedures were repeated using a new sample and the strain caseness rate was estimated at 31.5\%. However, this study did not discriminate between shore and sea-based personnel. ${ }^{7}$ The available evidence therefore suggests that military personnel deployed at sea appear to have higher rates of caseness (probable CMD or strain) than land-based personnel.

To further assess the effect of being deployed in the maritime environment the current study aimed to identify the personal, military and operational factors associated with mental health among a sample of RN personnel using data gathered while they were deployed at sea. Previous deployment studies of this kind have assessed PTSD caseness but not alcohol use as it is prohibited during combat operations. As previous mental health studies carried out among RN personnel focused solely on CMD, a broader range of mental health outcomes were assessed including probable PTSD symptoms and potentially harmful alcohol use.

\section{METHODS}

A paper-based survey was conducted among RN personnel (sailors and Royal Marines) while they were away on deployment using an adapted version of the questionnaire previously developed specifically for assessing operational mental health during land-based combat deployment. ${ }^{4}$ A survey design was chosen because it is an efficient way of gathering relatively detailed information about mental health and well-being from a large number of people in a brief period of time. ${ }^{8}$ Our previous surveys have shown that mental health studies must compete with the demands of deployment and the time available to conduct any studies of this kind are greatly reduced and constrained by ongoing operational duties. The survey was termed the Operational Mental Health Needs Evaluation (Maritime) (OMHNE (M)). Survey distribution was conducted face to face by the OMHNE team. A formal verbal briefing based on a written script was given by a survey team member to all participating personnel prior to questionnaire distribution. All participants were given the opportunity to refuse participation or to withdraw at any time. In all cases, absolute confidentiality was guaranteed prior to survey completion; the OMHNE(M) survey was anonymous. Implied consent was assumed when a survey was completed and returned.

\section{Population}

The study sample was composed of all Naval Service personnel (RN and Royal Marines) in four deployed warships; one was on a routine operational deployment and three were taking part in a maritime exercise in the Persian Gulf. All available personnel were invited to take part in the survey. Ethical approval for the study was granted by the Ministry of Defence Research Ethics Committee.

\section{Data collection}

The survey gathered information about basic sociodemographic, military and operational characteristics, current alcohol use and mental health. Measured background variables included Service background (RN or Royal Marines), rank, age, sex, length of service, relationship status and type of engagement (regular or reserve). Operational variables included ship's complement size (more or less than 300 personnel), type of deployment (routine deployment or maritime exercise) and whether personnel were deployed as a preformed group or drafted in specifically for the deployment. Additionally, the cumulative duration of maritime and land deployments over the past 3 years was assessed (categorised as more or less than 5 months). Events that occurred at home were asked about, including birth of a child, death or serious illness within loving relationships, intimate relationship breakdown, serious financial problems, problems with children and any other major problem at home while deployed. Positive answers were scored 1 , and negative responses scored 0 ; these were summed to yield a total score. Tertiles were computed and upper tertile scores (representing more home front problems) were compared to lower and middle tertile scores (representing fewer home front problems). Responses to three scales used in previous land-based OMHNEs, ${ }^{5}$ representing morale, leadership and group cohesion, each contained four items, which were each rated using four-point Likert scales representing levels of agreement. Agreeing with two or more items (out of four) on each scale represented a positive view and therefore higher levels of each factor. Of note, to enable easier comparisons, the cut-offs used throughout the study were consistent with those carried out in previous UK military research. ${ }^{45}$

Exposure to operational incidents, conceptualised as potentially traumatic events (PTEs), were assessed using a 17-item scale modified from the original operational experiences scale described by Hoge. ${ }^{9}$ The adaptation included the deletion of exposures specifically related to land deployments and the addition of maritime deployment experiences including boarding vessels, noncombatant evacuations, disaster relief and on-board emergencies. Responses were given to a five-item Likert scale representing increasing frequency of exposure. Exposure on one or more occasion represented a positive endorsement for each scale item. Endorsements were summed giving a count variable with a minimum score of 0 and a maximum of 17 . The scale was summed and tertiles were computed. Scores falling above the upper tertile, representing higher levels of exposure, were compared to the combined middle and lower tertile scores. Personnel were asked if they could remember receiving a psychoeducational brief dealing with deployment stress management before they deployed.

Mental health status was assessed using the 12-item General Health Questionnaire (GHQ-12), the PTSD Check ListCivilian version (PCL-C) and the three-item Alcohol Use Disorders Identification Test-C (AUDIT-C). The GHQ-12 is a measure of psychological distress, which represents symptoms of CMD. ${ }^{10-12}$ It has been routinely used in a variety of studies conducted into the mental health of UK Service personnel in

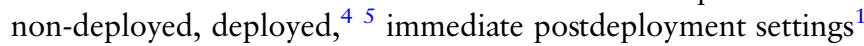
and in randomised controlled trials. ${ }^{13}$ The OMHNE (M) utilised the conventional cut-off of four or more symptom endorsements to indicate the presence of probable common mental disorder symptoms. This is consistent with the scoring methods used in other military studies and commensurate with the psychometric properties of the questionnaire. ${ }^{4-6}$

The PCL-C is a measure of Post-Traumatic Stress Disorder symptoms. ${ }^{14}$ In line with other OMHNE studies, which have used the PCL-C, the OMHNE (M) used a cut-off score of 50 or 
more to indicate 'caseness' or the presence of probable PTSD. Current alcohol use was assessed using the three-item AUDIT-C, a brief validated screening tool used to identify potential alcohol use disorders. ${ }^{15}$ Given the high prevalence of alcohol use in the UK AF, a higher AUDIT-C cut off score of $\geq 8$ rather than $\geq 4$ was used to indicate the presence of alcohol use potentially harmful to health.

Finally, although the character of maritime deployment is very different to land-based operations, to provide some military context, we compared the rates of mental disorder identified in the current study with those reported in previous operational surveys of UK personnel reported in Iraq in 2009 and Afghanistan in 2010 and 2011.

\section{Data analysis}

The data were analysed using the IBM Statistical Package for Social Sciences (SPSS) V.20. Frequency counts and proportions were generated for each survey item or transformed variable. The numbers and percentages described in this paper may not sum to sample totals due to missing data. Pearson's $\chi^{2}$ test was used to examine categorical data ${ }^{16}$ statistical probability was defined as $\mathrm{p}<0.05$ throughout. To further examine the relationship between dependant and independent variables, binary logistic regression was used to generate ORs with 95\% CIs, which were adjusted for potentially confounding variables.

\section{RESULTS}

The overall response rate was $77.2 \%(n=1393 / 1805)$ and the sociodemographic variables are described in table 1 . In total $41.2 \%(n=572 / 1387)$ of respondents, reported probable CMD symptoms, 7.8\% ( $\mathrm{n}=109 / 1389)$ reported probable PTSD caseness and 17.4\% $(n=242 / 1387)$ reported levels of alcohol use potentially harmful to health.

A number of sociodemographic factors were significantly associated with probable CMD or PTSD or harmful use of alcohol (table 1). CMD caseness levels were significantly greater among Royal Navy than Royal Marine personnel $(\mathrm{p}<0.05)$. Junior rates, respondents under the age of 25 years and those with service lengths less than 5 years were significantly more likely to report both CMD symptoms (all $\mathrm{p}<0.001$ ) and PTSD symptoms (all $p<0.001)$. Being male was significantly associated with problem drinking $(p<0.05)$. Sociodemographic factors found to be significant in univariable analyses were used as potentially confounding variables in the binary logistic regression models.

A number of operational factors were significantly associated with higher rates of CMD: lower morale $\left(\chi^{2}=205.77\right.$, df 1 , $\mathrm{p}<0.001)$, lower cohesion $\left(\chi^{2}=150.00\right.$, df $\left.1, \mathrm{p}<0.001\right)$ and poor perceived leadership $\left(\chi^{2}=93.45\right.$, df $\left.1, p<0.001\right)$; more problems on the home front $\left(\chi^{2}=44.78\right.$, df $\left.1, \mathrm{p}<0.001\right)$, type of deployment: planned exercise $\left(\chi^{2}=17.02\right.$, df $\left.1, p<0.001\right)$, greater exposure to PTEs $\left(\chi^{2}=25.12\right.$, df $\left.1, \mathrm{p}<0.001\right)$, nonreceipt of a stress brief $\left(\chi^{2}=5.00, \mathrm{df} 1, \mathrm{p}<0.05\right)$, greater cumulative duration of land deployments $\left(\chi^{2}=4.25\right.$, df $\left.1, p<0.05\right)$ and deployment in a smaller ship's company $\left(\chi^{2}=5.92\right.$, df 1 , $\mathrm{p}<0.05)$. There was no statistically significant association between CMD and the duration of maritime deployment, augmentee versus established group status or regular/reserve status.

Higher rates of PTSD was associated with lower morale $\left(\chi^{2}=55.00\right.$, df $\left.1, p<0.001\right)$, poor cohesion $\left(\chi^{2}=65.76\right.$, df 1 , $\mathrm{p}<0.001)$ and poorer perceived leadership $\left(\chi^{2}=93.45\right.$, df 1 , $\mathrm{p}<0.001)$, more problems on the home front $\left(\chi^{2}=48.65\right.$, df 1 , $\mathrm{p}<0.001)$, greater exposure to PTEs $\left(\chi^{2}=32.78, \mathrm{df} 1, \mathrm{p}<0.001\right)$ and longer duration of maritime deployments $\left(\chi^{2}=4.39\right.$, df 1 , $\mathrm{p}<0.05)$. There was no significant association with type of deployment, having received a predeployment stress brief, duration of land deployments, size of ship's company and regular versus reserve status.

Potentially harmful alcohol use was associated with being in a smaller ship's company $\left(\chi^{2}=15.59\right.$, df $\left.1, p<0.001\right)$ and being

Table 1 Association between sociodemographic variables and psychological disorder

\begin{tabular}{|c|c|c|c|c|c|c|}
\hline $\begin{array}{l}\text { Characteristic } \\
\text { n (\%) }\end{array}$ & $\begin{array}{l}\text { CMD cases } \\
\text { n (\%) }\end{array}$ & $\chi^{2}, \mathrm{df}, \mathrm{p}$ value & $\begin{array}{l}\text { PTSD cases } \\
\mathbf{n}(\%)\end{array}$ & $\chi^{2}, \mathrm{df}, \mathrm{p}$ value & $\begin{array}{l}\text { Problem drinking } \\
\text { cases } \mathrm{n}(\%)\end{array}$ & $\begin{array}{l}\chi^{2}, \mathrm{df}, \\
\mathrm{p} \text { value }\end{array}$ \\
\hline \multicolumn{7}{|l|}{ Service background } \\
\hline Royal Navy personnel 1224 (91.3) & $520 / 1219(42.7)$ & $5.89,1, p=<0.05$ & $101 / 1221(8.3)$ & $0.27,1, \mathrm{NS}$ & 218/1219 (17.9) & $0.76,1, \mathrm{NS}$ \\
\hline Royal Marines 116 (8.7) & $36 / 116(31.0)$ & & $8 / 116(6.9)$ & & $17 / 116(14.7)$ & \\
\hline \multicolumn{7}{|l|}{ Rank } \\
\hline Officer rank 195 (14.3) & $67 / 195(34.4)$ & $20.89,2, p=<0.001$ & $6 / 195(3.1)$ & $21.38,2, p=<0.001$ & $34 / 193(17.6)$ & $5.27,2, \mathrm{NS}$ \\
\hline Senior rating 295 (21.6) & 95/295 (32.2) & & $11 / 295(3.7)$ & & 64/294 (21.8) & \\
\hline Junior rating 876 (64.1) & $398 / 871(45.7)$ & & $92 / 873(10.5)$ & & 139/874 (15.9) & \\
\hline \multicolumn{7}{|l|}{ Age, years } \\
\hline Under 25402 (29) & $212 / 400(53.0)$ & $32.01,1, p=<0.001$ & $54 / 401(13.5)$ & $25.28,1, p=<0.001$ & 69/401 (17.2) & $0.02,1, \mathrm{NS}$ \\
\hline Over 25986 (71) & $359 / 984(36.5)$ & & $54 / 985(5.5)$ & & $172 / 982(17.5)$ & \\
\hline \multicolumn{7}{|l|}{ Sex } \\
\hline Male 1185 (85.9) & $484 / 1181(41.0)$ & $0.47,1$, NS & $92 / 1183(7.8)$ & $0.002,1, \mathrm{NS}$ & 216/1181 (18.3) & $4.80,1, p=<0.05$ \\
\hline Female 195 (14.1) & $85 / 195(43.6)$ & & 15/195 (7.7) & & 23/194 (11.9) & \\
\hline \multicolumn{7}{|l|}{ Relationship status } \\
\hline In a relationship 912 (65.7) & $359 / 908$ (39.5) & $3.34,1, \mathrm{NS}$ & $65 / 910(7.1)$ & $1.94,1, \mathrm{NS}$ & $157 / 908(17.3)$ & $0.03,1, \mathrm{NS}$ \\
\hline Not in a relationship 476 (34.3) & $212 / 475(44.6)$ & & $44 / 475(9.3)$ & & $84 / 475(17.7)$ & \\
\hline \multicolumn{7}{|l|}{ Length of service } \\
\hline $0-4$ years of service $463(35.9)$ & 245/461 (53.1) & $43.13,1, p=<0.001$ & $54 / 462(11.7)$ & $17.82,1, p=<0.001$ & $67 / 462(14.5)$ & $3.29,1, \mathrm{NS}$ \\
\hline 5 years or more service $826(64.1)$ & $283 / 824(34.3)$ & & $43 / 825(5.2)$ & & $152 / 823(18.5)$ & \\
\hline \multicolumn{7}{|l|}{ Regular or reserve engagement } \\
\hline Full-time service personnel 1367 (99.1) & $558 / 1362(41.0)$ & $1.48,1, \mathrm{NS}$ & $107 / 1364(7.8)$ & FET, 1, NS & 237/1362 (17.4) & FET, 1, NS \\
\hline Reservist $12(0.9)$ & $7 / 12(58.3)$ & & $0 / 12(0.0)$ & & $3 / 12(25.0)$ & \\
\hline
\end{tabular}


on a routine deployment $\left(\chi^{2}=12.94\right.$, df $\left.1, \mathrm{p}<0.001\right)$. There was no statistically significant association between problem drinking and duration of land deployments, having received a predeployment stress brief, morale, leadership, cohesion, problems on the home front, regular or reservist status. Of note alcohol consumption was not significantly associated with comorbid PTSD or CMD.

In adjusted binary logistic regression, lower morale, cohesion, better leadership and more home front problems were all significantly associated with CMD following adjustment for potential confounding variables including sociodemographic characteristics including rank, service, service length and age; operational factors including home front problems, exposure to potentially traumatic events, type of deployment, place of work, preoperational stress brief and land deployment; leadership, morale and cohesion were entered as a single block and finally all adjusting variables combined were adjusted for (table 2). Using the same procedure, following adjustment, probable PTSD remained significantly associated with lower morale, poorer perceived leadership and more problems on the home front (table 3). Following adjustment, potentially harmful alcohol use was significantly associated with deploying with a ship's company of less than 300 personnel (table 4).

Compared to data collected during land-based operations in Iraq in 2009 and Afghanistan in 2010 and 2011, the current study contained significantly greater numbers of personnel reporting symptoms of both CMD and PTSD. Compared to data gathered in Iraq where a CMD rate of $20.5 \%$ was reported, the rate of CMD in Afghanistan in 2010 was 17\% (OR 0.82, $95 \%$ CI 0.64 to 1.04 ) in 2011 it was $16 \%$ (OR $0.76,95 \%$ CI 0.59 to 0.97 ) and in the current study the rate was $41.2 \%$ (OR $2.79,95 \%$ CI 2.23 to 3.50 ). In Iraq, the rate of probable PTSD was $3.4 \%$, in Afghanistan in 2010, it was 2.8\% (OR 0.83, 95\% CI 0.48 to 1.43 ) in 2011 it was $1.8 \%$ (OR 0.53 , 95\% CI 0.29 to 0.96 ) and in the current study the probable PTSD rate was $7.8 \%$ (OR 2.49, 95\% CI 1.53 to 4.05 ).

\section{DISCUSSION}

\section{Main findings}

This study represents the first investigation, for a decade, into the mental health of RN and Royal Marine personnel deployed at sea and is the first to measure probable PTSD and alcohol misuse in the deployed maritime environment. The prevalence of CMD was $41.2 \%$, probable PTSD $7.8 \%$ and harmful alcohol use $17.4 \%$. Reporting probable CMD was associated with lower morale, poorer perceived leadership, lower group cohesion and problems on the home front. PTSD was associated with lower morale, poorer perceived leadership, more problems on the home front and greater exposure to PTEs. Potentially harmful alcohol use was only significantly associated with serving in smaller vessels containing less than 300 personnel.

\section{Study limitations}

Since this is a cross-sectional study, it is not possible to infer the direction of cause among the outcomes assessed. ${ }^{8}$ Participants were assessed while working in an arduous operational environment and the rates of probable disorder found in this study may represent a psychological response to being at sea for a prolonged period rather than personnel's normal state of mental well-being. If measured postdeployment or following the completion of the exercise, different outcomes may well have been reported. However, given the outcome of a previous study among RN personnel indicating decreased mental health at sea and that the current study sampled data in two different operational areas, the results seem representative given the environment in which they were reported. Also there is no reason to consider that the psychological morbidity or functional impairment caused by symptoms experienced at sea should have any less impact than such symptoms experienced in other environments. Baseline mental health was not measured and it might be that some personnel had higher predeployment levels of mental ill-health. Of note, all personnel were assessed predeployment as fit for work in their fulltime primary occupational roles. However, as longitudinal data were not gathered, it is not possible to assess the contribution of baseline mental health to the psychological distress measured in this study. Furthermore, in keeping with most other epidemiological studies our survey comprised of self-report measures which are not diagnostic as they lack the rigour of an objective clinical assessment of mental health. Lastly, it is important to note that this sample did not include submarines or smaller patrol vessels so the results may not be generalisable to all deployed maritime roles.

\section{Prevalence of mental health problems}

Results from previous research among $\mathrm{RN}$ personnel serving at sea, conducted a decade ago, indicated a CMD rate of $41 \%{ }^{6}$ which was similar to the current rate of $41.2 \%$. However, while further historical measures of Naval personnel's mental health are not available as comparators, it is noteworthy that the RN's daily ration of rum was designed to help sailors to cope not only with the hazards of combat but also with routine life on a vessel afloat. ${ }^{17}$ Data collected a decade apart suggests that the substantial rate of CMD symptoms found among deployed personnel at sea is persistent and is significantly higher than rates found among military personnel in the non-deployed setting and during deployment to land-based operations. Taken together these results suggest that maritime deployment has potentially adverse effects on sailor's mental health and the main associates of poorer mental health include lower perceived levels of leadership, lower self-reported morale and cohesion, greater levels of non-operational stress in the form of events occurring at home and for PTSD symptoms, greater exposure to PTEs.

Given the RN's centuries long association with alcohol, one might expect a high prevalence of disorder among deployed personnel. Indeed, an earlier study of problem drinking in the $\mathrm{RN}$ reported that $57 \%$ of personnel scored $\geq 8$ on a modified version of the AUDIT-C. ${ }^{18}$ By comparison, this study reported a $17.4 \%$ prevalence, which is markedly lower, but remains higher than the $13 \%$ prevalence found in troops in home-base locations. $^{1}$

Naval personnel working in an operational environment reported drinking alcohol in a potentially harmful fashion. What cannot be easily ascertained is if this reflects their drinking behaviour at sea or when given shore leave. One possible explanation for the study findings being lower than previous research among RN personnel may be related to reduced access to alcohol during a maritime deployment since personnel are only allowed to drink alcohol if they are unlikely to be required for on-board ship duties; other than during short periods of shore leave, opportunities to consume alcohol excessively or consistently are rare during exercises or operational deployments which were the focus of this study. However, the sample time-frame of the AUDIT-C should represent drinking behaviour over recent times, not just a single event.

Previous versions of the OMHNE have been used within land-based operational environments ${ }^{4}$ and consistently found 
Table 2 Binary logistic regression of those military operational characteristics associated with common mental disorder (CMD)

\begin{tabular}{|c|c|c|c|c|c|c|c|c|}
\hline Characteristic & $\begin{array}{l}\text { Characteristic total } \\
\text { n (\%) }\end{array}$ & $\begin{array}{l}\text { CMD no case } \\
\mathrm{n}(\%)\end{array}$ & $\begin{array}{l}\text { CMD case } \\
\mathbf{n}(\%)\end{array}$ & OR $(95 \% \mathrm{Cl})$ & $\mathrm{AOR}^{*}(95 \% \mathrm{Cl})$ & AORt $(95 \% \mathrm{Cl})$ & $\mathrm{AOR} \ddagger(95 \% \mathrm{Cl})$ & AOR§ $(95 \% \mathrm{Cl})$ \\
\hline Lower morale & $701(53.7)$ & $281(40.1)$ & $420(59.9)$ & $5.74(4.48$ to 7.36$)$ & $6.02(4.58$ to 7.90$)$ & $5.94(4.46$ to 7.91$)$ & $3.83(2.93$ to 5.00$)$ & 4.02 (2.88 to 5.63$)$ \\
\hline Higher morale & $605(46.3)$ & $480(79.3)$ & $125(20.7)$ & 1 & 1 & 1 & 1 & 1 \\
\hline Lower cohesion & $360(26.0)$ & $113(31.4)$ & $247(68.6)$ & 4.72 (3.64 to 6.12$)$ & 4.58 (3.46 to 6.07$)$ & 4.46 (3.34 to 5.97$)$ & 2.66 (1.97 to 3.58$)$ & 2.75 (1.90 to 3.97$)$ \\
\hline Higher cohesion & $1026(74.0)$ & $701(68.3)$ & $325(31.7)$ & 1 & 1 & 1 & 1 & 1 \\
\hline Lower leadership & $250(18.0)$ & $86(34.4)$ & $164(65.6)$ & 3.40 (2.55 to 4.54$)$ & 2.95 (2.16 to 4.03$)$ & 3.58 (2.58 to 4.97$)$ & 1.76 (1.26 to 2.46$)$ & 1.65 (1.10 to 2.47$)$ \\
\hline Higher Leadership & $1136(82.0)$ & $728(64.1)$ & $408(35.9)$ & 1 & 1 & 1 & 1 & 1 \\
\hline Greater problems on the home front & $429(33.1)$ & $197(45.9)$ & $232(54.1)$ & 2.22 (1.76 to 2.81$)$ & 2.28 (1.76 to 2.95$)$ & 2.17 (1.68 to 2.80$)$ & 2.21 (1.68 to 2.91$)$ & 2.46 (1.78 to 3.38$)$ \\
\hline Fewer problems on the home front & $866(66.9)$ & $566(65.4)$ & $300(34.6)$ & 1 & 1 & 1 & 1 & 1 \\
\hline Planned exercise & $1159(83.6)$ & $653(56.3)$ & $506(43.7)$ & 1.90 (1.40 to 2.59$)$ & 2.26 (1.64 to 3.13$)$ & 2.41 (1.50 to 3.88$)$ & $1.24(0.86$ to 1.79$)$ & $2.50(1.40$ to 4.46$)$ \\
\hline Routine deployment & $228(16.4)$ & $162(71.1)$ & $66(28.9)$ & 1 & 1 & 1 & 1 & 1 \\
\hline Greater exposure to potentially traumatic events & 467 (33.8) & $231(49.5)$ & $236(50.5)$ & 1.78 (1.42 to 2.23$)$ & 1.60 (1.25 to 2.05$)$ & 1.69 (1.31 to 2.18$)$ & 1.44 (1.11 to 1.88$)$ & $1.17(0.85$ to 1.62$)$ \\
\hline Lower exposure to potentially traumatic events & $915(66.2)$ & $581(63.5)$ & $334(36.5)$ & 1 & 1 & 1 & 1 & 1 \\
\hline No preoperational stress brief & $1200(87.5)$ & $692(57.7)$ & $508(42.3)$ & 1.47 (1.05 to 2.06$)$ & 1.81 (1.26 to 2.61$)$ & 1.42 (0.97 to 2.08$)$ & 1.07 (0.73 to 1.56$)$ & $1.29(0.82$ to 2.02$)$ \\
\hline Received preoperational stress brief & $171(12.5)$ & $114(66.7)$ & $57(33.3)$ & 1 & 1 & 1 & 1 & 1 \\
\hline Land deployments: $<5$ months & $1017(78.5)$ & $579(56.9)$ & $438(43.1)$ & $1.33(1.01$ to 1.75$)$ & 0.97 (0.71 to 1.33$)$ & 1.42 (1.06 to 1.91$)$ & $1.26(0.92$ to 1.73$)$ & 0.93 (0.63 to 1.37$)$ \\
\hline Land deployments: $>5$ months & $279(21.5)$ & $178(63.8)$ & $101(36.2)$ & 1 & 1 & 1 & 1 & 1 \\
\hline Place of work: ships $>300$ personnel & $1004(72.4)$ & $570(56.8)$ & $434(43.2)$ & 1.35 (1.06 to 1.72$)$ & 1.57 (1.21 to 2.04$)$ & 0.95 (0.65 to 1.39$)$ & 0.80 (0.59 to 1.07$)$ & $0.63(0.39$ to 1.00$)$ \\
\hline Place of work: ships $<300$ personnel & $383(27.6)$ & $245(64.0)$ & $138(36.0)$ & 1 & 1 & 1 & 1 & 1 \\
\hline
\end{tabular}

*Adjusted for sociodemographic factors (rank, service, service length and age).

†Adjusted for operational factors (home front problems, exposure to potentially traumatic events, type of deployment, place of work, preoperational stress brief and land deployment).

¥Adjusted for leadership, morale and cohesion.

$\S$ Adjusted for all. AOR, adjusted odds ratio. 
Table 3 Binary logistic regression of those military operational characteristics associated with post-traumatic stress disorder (PTSD)

\begin{tabular}{|c|c|c|c|c|c|c|c|c|}
\hline Characteristic & $\begin{array}{l}\text { Characteristic total } \\
\mathbf{n}(\%)\end{array}$ & $\begin{array}{l}\text { PTSD no case } \\
\mathrm{n}(\%)\end{array}$ & $\begin{array}{l}\text { PTSD case } \\
\text { n (\%) }\end{array}$ & $\begin{array}{l}\text { OR } \\
(95 \% \mathrm{Cl})\end{array}$ & $\mathrm{AOR}^{*}(95 \% \mathrm{Cl})$ & AORt $(95 \% \mathrm{Cl})$ & AOR $\ddagger(95 \% \mathrm{Cl})$ & AOR§ $(95 \% \mathrm{Cl})$ \\
\hline Lower morale & $702(53.7)$ & $610(86.9)$ & $92(13.1)$ & 7.47 (4.05 to 13.77$)$ & 6.46 (3.39 to 12.32$)$ & $5.96(3.18$ to 11.40$)$ & 3.80 (1.97 to 7.34$)$ & 2.98 (1.40 to 6.35$)$ \\
\hline Higher morale & $606(46.3)$ & $594(98.0)$ & $12(2.0)$ & 1 & 1 & 1 & 1 & 1 \\
\hline Lower cohesion & $361(26.0)$ & $297(82.3)$ & $64(17.7)$ & 4.70 (3.14 to 7.04$)$ & 4.00 (2.60 to 6.16$)$ & $4.08(2.57$ to 6.46$)$ & 2.13 (1.34 to 3.39$)$ & $1.72(0.98$ to 3.03$)$ \\
\hline Higher cohesion & $1027(74.0)$ & $982(95.6)$ & $45(4.4)$ & 1 & 1 & 1 & 1 & 1 \\
\hline Lower leadership & $251(18.1)$ & $194(77.3)$ & $57(22.7)$ & 6.13 (4.09 to 9.20$)$ & 5.27 (3.62 to 8.26$)$ & 5.90 (3.72 to 9.35$)$ & 3.51 (2.24 to 5.51$)$ & 3.31 (1.91 to 5.72$)$ \\
\hline Higher leadership & $1137(81.9)$ & $1085(95.4)$ & $52(4.6)$ & 1 & 1 & 1 & 1 & 1 \\
\hline Greater problems on the home front & $429(33.1)$ & $362(84.4)$ & 67 (13.6) & 4.04 (2.66 to 6.13$)$ & 4.63 (2.94 to 7.31$)$ & 3.89 (2.47 to 6.11$)$ & 3.58 (2.27 to 5.64$)$ & 4.36 (2.58 to 7.39$)$ \\
\hline Fewer problems on the home front & $867(66.9)$ & $829(95.6)$ & $38(4.4)$ & 1 & 1 & 1 & 1 & 1 \\
\hline Greater exposure to potentially traumatic events & $468(33.8)$ & $404(86.3)$ & $64(13.7)$ & 3.07 (2.06 to 4.57$)$ & 2.72 (1.75 to 4.22 ) & $2.52(1.62$ to 3.93$)$ & 2.41 (1.56 to 3.71$)$ & $2.08(1.23$ to 3.51$)$ \\
\hline Lower exposure to potentially traumatic events & $916(66.2)$ & $871(95.1)$ & $45(4.9)$ & 1 & 1 & 1 & 1 & 1 \\
\hline Maritime deployments $>5$ months & $951(68.8)$ & $867(91.2)$ & $84(8.8)$ & 1.64 (1.03 to 2.63$)$ & 1.76 (1.06 to 2.96$)$ & $1.44(0.85$ to 2.45$)$ & 1.45 (0.89 to 2.37$)$ & $1.55(0.83$ to 2.91$)$ \\
\hline Maritime deployments $<5$ months & $431(31.2)$ & 407 (94.4) & $24(5.6)$ & 1 & 1 & 1 & 1 & 1 \\
\hline
\end{tabular}

*Adjusted for sociodemographic factors (rank, service, service length and age).

†Adjusted for Operational Factors (home front problems, exposure to potentially traumatic events, type of deployment, place of work, pre operational stress brief, land deployment).

¥Adjusted for leadership, morale and cohesion.

$\S$ Adjusted for all. AOR, adjusted odds ratio.

Table 4 Binary logistic regression of those military operational characteristics associated with problem drinking

\begin{tabular}{|c|c|c|c|c|c|c|c|c|}
\hline Characteristic & $\begin{array}{l}\text { Characteristic total } \\
\mathrm{n}(\%)\end{array}$ & $\begin{array}{l}\text { Alcohol no case } \\
\text { n (\%) }\end{array}$ & $\begin{array}{l}\text { Alcohol case } \\
\text { n (\%) }\end{array}$ & OR $(95 \% \mathrm{Cl})$ & $\mathrm{AOR}^{*}(95 \% \mathrm{Cl})$ & AORt $(95 \% \mathrm{Cl})$ & AOR $\ddagger(95 \% \mathrm{Cl})$ & AOR§ $(95 \% \mathrm{Cl})$ \\
\hline Place of work: ships $<300$ personnel & $379(27.3)$ & $288(76.0)$ & $91(24.0)$ & 1.79 (1.34 to 2.40$)$ & 1.81 (1.33 to 2.48$)$ & 1.76 (1.11 to 2.79$)$ & 1.97 (1.43 to 2.71$)$ & 1.78 (1.05 to 3.03$)$ \\
\hline Place of work: ships $>300$ personnel & $1008(72.7)$ & $857(85.0)$ & $151(15.0)$ & 1 & 1 & 1 & 1 & 1 \\
\hline Routine deployment & $225(16.2)$ & $167(74.2)$ & $58(25.8)$ & 1.85 (1.32 to 2.59$)$ & 1.92 (1.35 to 2.73 ) & 1.08 (0.64 to 1.21$)$ & 2.18 (1.50 to 3.16$)$ & 1.29 (0.71 to 2.34$)$ \\
\hline Planned exercise & $1162(83.8)$ & $978(84.2)$ & $184(15.8)$ & 1 & 1 & 1 & 1 & 1 \\
\hline
\end{tabular}

*Adjusted for sociodemographic factors (rank, service, service length and age).

†Adjusted for operational factors (home front problems, exposure to potentially traumatic events, type of deployment, place of work, preoperational stress brief and land deployment).

¥Adjusted for leadership, morale and cohesion.

$\S$ Adjusted for all. AOR, adjusted odds ratio. 
significantly lower rates of PTSD than the rate of $7.8 \%$ reported in this study. The rate of PTSD is higher than that reported in other studies of UK AF personnel where the rates vary between $1.3 \%$ and $4.8 \%$; it is also substantially higher than rates reported among the general military population $(\sim 3 \%){ }^{20}$ The higher rate of probable PTSD requires some explanation. It may be that the nature of exposure to operational events within the maritime force is different to combat-related PTEs encountered during land-based deployments. ${ }^{9}$ The level of exposure, as measured by our adapted survey tool, was low; mean exposure was 2 potentially traumatic events with $46.8 \%(n=652)$ reporting no exposure at all. Jones et al, ${ }^{19}$ suggest that other factors unrelated to deployment may leave personnel vulnerable to PTSD. It may be that because of their lack of routine exposure to land combat traumatic events $\mathrm{RN}$ personnel may disproportionately suffer from the effects of prior land-based deployment; indeed $21.5 \%$ of the sample had previously deployed for more than 5 months on land-based operations. Other possible explanations for the finding may be greater baseline symptoms which were not measured in this study or because there are other aspects of maritime service which we could not account for that are important risk factors for developing PTSD symptoms. An exploration of the sociodemographic characteristics of the sample suggested that young, junior rate personnel with short service lengths reported the highest levels of psychological symptoms and it may be that they are particularly adversely affected by maritime deployment or have accumulations of risk factors that are not pertinent to older personnel. PTSD symptoms measured by questionnaire may not be PTSD specific but may represent a general index of deployment stress, which is particularly high during maritime deployment.

\section{Leadership, cohesion and morale}

Lower levels of both perceived leadership and lower morale were associated with increased symptoms of CMD and PTSD. Higher unit cohesion was also inversely associated with CMD symptom levels. Overall, $82 \%$ of participants reported high satisfaction with leadership and $74 \%$ better cohesion while a lesser proportion, $46.3 \%$, reported high levels of morale. A previous study into the mediating effect of cohesion on CMD and PTSD within UK land forces reported a positive association between greater cohesion and less mental ill-health. ${ }^{21}$ Equally, greater team cohesion has previously been associated with better morale and improved work performance. ${ }^{22}$ Although high perceived levels of leadership and cohesion were observed in the current study, mental health symptoms were substantial; however, levels of morale were comparatively lower than those measured during previous land-based OMHNEs. The current study found that $46.3 \%$ of personnel reported higher levels of morale whereas previous OMHNEs found that $76.5 \%$ of personnel did so. ${ }^{5}$ It is difficult to ascertain why morale was low within the sample population given the high satisfaction with leadership and cohesion. A study of police personnel reported that high morale and less distress were associated with adequate resources to meet demands and suggested that this was less about worker adaptability and more about the ability of the wider organisation to adapt to demands. ${ }^{23}$ It is unclear whether this is germane to the RN. It may be that deployed maritime personnel while well led and adept at working in teams in the non-deployed setting, are vulnerable to the effects of stress as a consequence of lower morale when deployed on maritime operations Further, longitudinal research may help to understand whether this is a deployment-specific phenomenon that personnel recover from on return to the UK. Further qualitative research may offer greater insight into the reasons why sailors may experience lower morale when on routine deployments or planned exercises.

\section{Problems on the home front}

Within this study, both CMD and PTSD were associated with problems on the home front; this is consistent with other military research findings. For instance, a previous report of mobilised reserves suggested that deployment was associated with increased odds of experiencing relationship problems compared to non-mobilised reserves. ${ }^{24}$ In addition, problems on the home front may occur as a consequence of a lack of geographic stability experienced by Naval families who often move every 23 years as the service person changes job. All service personnel experience episodic family separation including deployments which can last many months and carry a risk of injury or death. These experiences are challenges for family members in spite of there being an expectation that families adapt to military culture. ${ }^{25}$ These challenges can be stressful for all family members potentially leading to increased conflict within family, parental and spouse relationships. ${ }^{26}$ Although the current study cannot indicate the direction of cause, it does highlight the importance of the mental health impact of problems on the home front for deployed personnel. Empirical evidence suggests that deployed military personnel have better mental health if they perceive their families back at home are well supported. ${ }^{27}$ This finding suggests that the RN may wish to assess how well families are supported during deployments and if found to be lacking, investigate novel ways of supporting families in order to bolster the mental health of deployed personnel.

\section{CONCLUSION}

To conclude, our data suggests that the deployed maritime environment is particularly challenging since the probable rates of CMD and PTSD among deployed maritime personnel are higher than those found in other UK AF members including rates reported during deployment to high threat locations such as Iraq or Afghanistan over the past 10-years. Rates of problem drinking in deployed $\mathrm{RN}$ personnel were lower than those found in a previous study but higher than the wider UK AF and seem to have a minimal association with operational characteristics. Reasons for the higher rates of probable PTSD among deployed RN personnel compared to those who are shore based are not wholly clear but may be more strongly associated with problems on the home front and exposure to different PTEs to those found in land-based deployments. The high prevalence of PTSD and CMD warrants further investigation to better understand whether they are specifically related to operational deployment, though it is notable that maritime military surveys suggest a generally higher symptom prevalence among $\mathrm{RN}$ personnel. Given the association between mental disorder and problems on the home front, further investigation may be required to establish whether collaborative approaches between welfare support and medical services which span the deployment cycle may have benefits for the mental health of deployed maritime personnel.

\section{Twitter Follow Dean Whybrow at @dwhyb}

Competing interests All authors are serving or retired members of the armed forces and the study was focused on military personnel. DW worked as a Visiting Researcher within the Academic Department of Military Mental Health at King's College, London while the study was being carried out.

Ethics approval Ministry of Defence Research Ethics Committee.

Provenance and peer review Not commissioned; externally peer reviewed. 
Open Access This is an Open Access article distributed in accordance with the Creative Commons Attribution Non Commercial (CC BY-NC 4.0) license, which permits others to distribute, remix, adapt, build upon this work non-commercially, and license their derivative works on different terms, provided the original work is properly cited and the use is non-commercial. See: http://creativecommons.org/ licenses/by-nc/4.0/

\section{REFERENCES}

1 Fear NT, Jones $M$, Murphy $\mathrm{D}$, et al. What are the consequences of deployment to Iraq and Afghanistan on the mental health of the UK armed forces? A cohort study. Lancet 2010;375:1783-97.

2 NICE. CG 123. Common mental health disorders: identification and pathways to care. London: National Institute of Health and Clinical Excellence, 2011.

3 Limbert C. Psychological well-being and job satisfaction amongst military personnel on unaccompanied tours: the impact of perceived social support and coping strategies. Mil Psychol 2004;16:37-51.

4 Mulligan $\mathrm{K}$, Jones N, Woodhead $\mathrm{C}$, et al. Mental health of UK military personnel while on deployment in Iraq. Br J Psychiatry 2010;197:405-10.

5 Jones N, Mitchell P, Clack J, et al. Mental health and psychological support in UK armed forces personnel deployed to Afghanistan in 2010 and 2011. Br J Psychiatry 2014;204:157-62.

6 Bridger $\mathrm{R}$, Kilminster $\mathrm{S}$, Slaven $\mathrm{G}$. Occupational stress and strain in the naval service: 1999 and 2004. Occup Med 2007;57:92-7.

7 Bridger R. Naval Service Cohort Study of Occupational Stress: background to the research and a review of the latest findings. J $R$ Nav Med Serv 2008;94:22-30.

8 Bryman A. Social research methods. 4th edn. Oxford, New York: Oxford University Press, 2012.

9 Hoge CW, Castro CA, Messer SC, et al. Combat duty in Iraq and Afghanistan, mental health problems, and barriers to care. N Engl J Med 2004;351:13-22.

10 Goldberg D, Williams P. A user's guide to the general health questionnaire. Windsor: Nelson, 1988

11 Goldberg D, Gater R, Sartorious N. The validity of two versions of the GHQ in the WHO study of mental illness in general health care. Psychol Med 1997;27:191-7.

12 Lesage F, Martens-Resende S, Deschamps F, et al. Validation of the General Health Questionnaire (GHQ-12) adapted to a work-related context. Open J Preventitive Med 2011;1:44-8.
13 Greenberg N, Langston V, Everitt B, et al. A cluster randomized controlled trial to determine the efficacy of Trauma Risk Management (TRiM) in a military population. J Trauma Stress 2010;23:430-6.

14 Blanchard EB, Jones-Alexander J, Buckley TC, et al. Psychometric properties of the PTSD Checklist (PCL). Behav Res Ther 1996;34:669-73.

15 Bradley KA, DeBenedetti AF, Volk RJ, et al. AUDIT-C as a brief screen for alcoho misuse in primary care. Alcohol Clin Exp Res 2007;31:1208-17.

16 Dancey CP, Reidy J. Statistics without maths for psychology. Harlow, England: Prentice Hall/Pearson, 2011.

17 Jones E, Fear N. Alcohol use and misuse within the military: a review. Int Rev Psychiatry 2011;23:166-72.

18 Henderson A, Langston V, Greenberg N. Alcohol misuse in the Royal Navy. Occup Med 2009;59:25-31.

19 Jones M, Sundin J, Goodwin L, et al. What explains post-traumatic stress disorder (PTSD) in UK service personnel: deployment or something else? Psychol Med 2013:43:1703-12.

20 Macmanus D, Jones N, Wesseley $\mathrm{S}$, et al. The mental health of the UK Armed Forces in the 21st century: resilience in the face of adversity. J Royal Army Med Corp 2014;160:125-30.

21 Du Preez J, Sundin J, Wessely $\mathrm{S}$, et al. Unit cohesion and mental health in the UK armed forces. Occup Med 2012;62:47-53.

22 Mael FA, Alderks CE. Leadership team cohesion and subordinate work unit morale and performance. Mil Psychol 1993;5:141-58.

23 Dollard MF, Osborne K, Manning I. Organization-environment adaptation: a macro-level shift in modeling work distress and morale. J Organ Behav 2013;34:629-47.

24 Harvey SB, Hatch SL, Jones $\mathrm{M}$, et al. The long-term consequences of military deployment: a 5-year cohort study of United Kingdom reservists deployed to Iraq in 2003. Am J Epidemiol 2012;176:1177-84.

25 Padden D, Agazio J. Caring for military families across the deployment cycle. J Emerg Nurs 2013;39:562-9.

26 Laser J, Stephens P. Working with military families through deployment and beyond. Clin Soc Work J 2011;39:28-38.

27 Mulligan $\mathrm{K}$, Jones $\mathrm{N}$, Davies $\mathrm{M}$, et al. Effects of home on the mental health of British forces serving in Iraq and Afghanistan. Br J Psychiatry 2012;201: 193-8. 